\title{
IT Future of Medicine: Next Generation Sequencing is the Key to Future Personalized Medicine
}

\author{
Hans Lehrach and Babette Regierer for the IT Future of Medicine Consortium \\ Max Planck Institute for Molecular Genetics, \\ Berlin, Germany \\ http://www.itfom.eu/
}

The IT Future of Medicine (ITFOM) initiative will produce computational models of individuals to enable the prediction of their future health risks, progression of diseases and selection and efficacy of treatments while minimizing side effects. As one of six Future and Emerging Technologies (FET) Flagship Pilot Projects funded by the European Commission, ITFoM will foster the integration of technology development in functional genomics and computer technologies to enable the generation of patient models to make them available for clinical application. The realization of the patient model is based on the recent breakthroughs in sequencing technology that enables the high-throughput analysis of a large number of individual genomes and transcriptomes. The genome profile will be integrated with proteome and metabolome information generated via new powerful chromatography, mass spectrometry and nuclear magnetic resonance techniques. Computational and mathematical tools enable the development of systems approaches for deciphering the functional and regulatory networks underlying the complex biological systems and form the basis for the future patient model.

The recent increases in the capacity of next-generation sequencing systems will provide huge amounts of genome, epigenome and transcriptome data, making it feasible to apply deep sequencing in the clinic to characterize not only the patient's genome, but also individual samples e.g. from tumors. The -omics information will provide the basis to establish integrated molecular, physiological and anatomical models of every individual in the health care system. The first approach to the "Virtual Patient" modeling system that has been generated at the Max Planck Institute for Molecular Genetics combines general information available about cancer relevant pathways with the individual tumor/patient information (genome, transcriptome). This individualized model will not only be able to analyze the current situation, but will allow the prediction of the response of the patient to different therapy options or intolerance for certain drugs.

IT Future of Medicine will have long lasting beneficial effects for medicine of the future offering new routes to improve clinical practice, reduce health care costs but also to accelerate the development and the approval process for new drugs.

IT Future of Medicine is an initiative of more than 50 academic and industrial partners from over 15 countries to set up a research concept for the development of the "virtual patient".

\section{References}

1. Manolopoulos VG, Dechairo B, Huriez A, Kühn A, LLerena A, van Schaik RH, Yeo K-TJ, Ragia G, and Siest G (2011): Pharmacogenomics and personalized medicine in clinical practice Pharmacogenomics 12(5):597610. doi:10.2217/pgs.11.14.

2. Daskalaki A, Wierling C, Herwig R (2009): Computational tools and resources for systems biology approaches in cancer. In Computational Biology - Issues and Applications in Oncology, Series: Applied Bioinformatics and Biostatistics in Cancer Research, Pham, Tuan (Ed.), Springer, New York Dordrecht Heidelberg London. 2009:227-242.

\section{Relevant Web sites}

4. http://www.itfom.eu/

5. http://www.fet-f.eu/

6. http://www.molgen.mpg.de/research/lehrach/ 